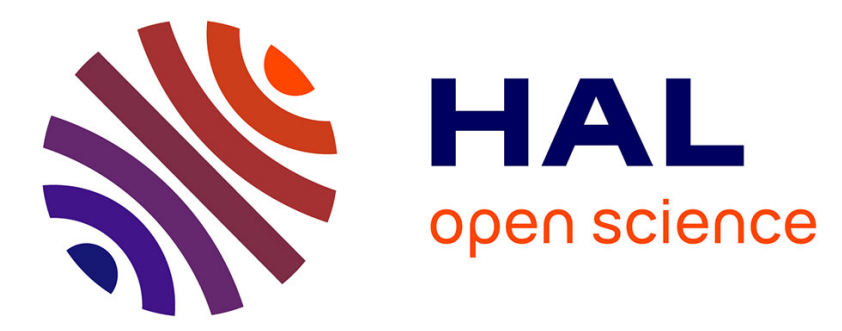

\title{
Paramagnetism and martensite stabilization of tensile strained NiTi shape memory alloy
}

\author{
A. Kyianytsia, E. Gaudry, M. Ponçot, Pascal Boulet, B. Kierren, Thomas
}

Hauet

\section{- To cite this version:}

A. Kyianytsia, E. Gaudry, M. Ponçot, Pascal Boulet, B. Kierren, et al.. Paramagnetism and martensite stabilization of tensile strained NiTi shape memory alloy. Applied Physics Letters, 2020, 117 (12), pp.122411. 10.1063/5.0020145 . hal-02948734

\section{HAL Id: hal-02948734 \\ https://hal.univ-lorraine.fr/hal-02948734}

Submitted on 25 Sep 2020

HAL is a multi-disciplinary open access archive for the deposit and dissemination of scientific research documents, whether they are published or not. The documents may come from teaching and research institutions in France or abroad, or from public or private research centers.
L'archive ouverte pluridisciplinaire HAL, est destinée au dépôt et à la diffusion de documents scientifiques de niveau recherche, publiés ou non, émanant des établissements d'enseignement et de recherche français ou étrangers, des laboratoires publics ou privés. 


\title{
Paramagnetism and martensite stabilization of tensile strained NiTi shape memory alloy
}

\author{
A. Kyianytsia ${ }^{1}$, E. Gaudry ${ }^{1}$, M. Ponçot ${ }^{1}$, P. Boulet $^{1}$, B. Kierren ${ }^{1}$ and T. Hauet ${ }^{1}$ \\ ${ }^{1}$ Institut Jean Lamour, Université de Lorraine-CNRS, Nancy, 54000, France
}

\begin{abstract}
We present an experimental and theoretical study of Pauli paramagnetism and martensite stabilization in a near equiatomic NiTi shape memory alloy. We demonstrate a direct correlation between strain-induced shear of the B19' NiTi lattice and its electronic and thermodynamical features. An increase of the monoclinic angle $\beta$ from 97.4 to 98 degrees induces a $7 \%$ decrease of the magnetic susceptibility because of a shift and deepening of a dip in B19' density of state at the Fermi level. It also produces a decrease of the B19' enthalpy, which translates into an increase of the martensite-to-austenite transition temperature by $60 \mathrm{~K}$.
\end{abstract}

Near equiatomic NiTi alloys carry remarkable properties such as shape memory effect and pseudoelasticity. Both effects are born of first-order reversible phase transformation between lowsymmetry monoclinic B19' martensite phase and highsymmetry cubic B2 austenite phase. Tuning the transition temperatures and martensite transformation hysteresis has been a constant objective. It has yet been achieved by adjusting $\mathrm{Ni}_{\mathrm{x}} \mathrm{Ti}_{1-\mathrm{x}}$ concentration [1] or by substituting element in ternary NiTiX alloys (with $\mathrm{X}=\mathrm{Hf}, \mathrm{Pd}, \mathrm{Cu}, \ldots)[2,3]$. Geometrical compatibility of B19' and B2 phases [4], change of valence electron number [5] and thermodynamics [1,6] have been investigated to explain the influence of theses chemical changes on NiTi-based alloys characteristics. Interestingly, no direct correlation between electronic features, transition temperatures and $\mathrm{NiTi}$ lattice distortion for a fixed concentration has yet been demonstrated, whereas the complex microstructure of NiTi under strain has been heavily studied [7-9]. Moreover, magnetism, which is known as a good probe of the electronic properties, has been rarely studied in NiTi alloys [10-13], although its impact on the magnetic resonance imaging of NiTi-based stents and biomedical implants has often been highlighted $[14,15]$.

Here, we perform systematic X-ray diffraction (XRD) and magnetization measurements in order to characterize the influence of the tensile strain on both the martensite-to-austenite transition temperature and magnetic susceptibility of a $\mathrm{NiTi}$ sheet. Ab-initio calculations correlate the measured strain-induced shear of the martensite lattice to particular features of the B19' energy and density of states at the Fermi level.

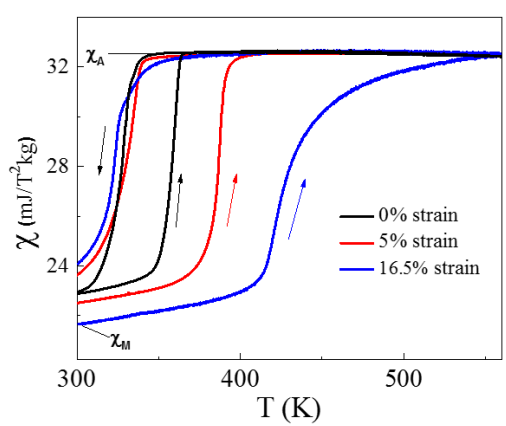

Figure 1. Magnetic susceptibility $\chi$ of NiTi versus temperature for as grown sample (black curve), 5\% strained sample (red curve), $16.5 \%$ strained sample (blue curve).

We use NiTi $(50.6$ at $\% \mathrm{Ti} ; 49.4$ at $\% \mathrm{Ni} \pm$ $0.5 \%$ ) free-standing polycrystalline $20 \mu \mathrm{m}$ thick sheets, grown by DC magnetron sputtering as described in details in Ref. [16]. Fig.1 shows the DC Magnetic susceptibility $\chi$ measured by SQUID magnetometer as a function of temperature under a constant magnetic field of 2T. Magnetic field is applied in the plane of the NiTi sheet. Note that $\chi$ does not depend on the measurement direction in the film plane because of the polycrystalline nature of the NiTi sheet. As-grown NiTi sample overcomes a hysteretic transition between a value $\chi_{\mathrm{M}}=23 \mathrm{~mJ} \cdot \mathrm{T}^{-2} \cdot \mathrm{kg}^{-1}$ in the martensite phase and $\chi_{\mathrm{A}}=32.5 \mathrm{~mJ} \cdot \mathrm{T}^{-2} \cdot \mathrm{kg}^{-1}$ in the austenite phase, in agreement with [10]. A magnetic transition temperature of around $360 \mathrm{~K}(330 \mathrm{~K})$ matches the martensite-to-austenite (respectively austenite-tomartensite) transition in XRD curves, in agreement with $[8,17]$ for similar concentrations. Tensile tests are performed using a Deformation Device System 
commercialized by Kammrath \& Weiss at $2 \mu \mathrm{m} / \mathrm{s}$ and room temperature, i.e. in the martensite phase. During stretching, elongation of the specimen is measured by a linear displacement gauge while the corresponding force is recorded. 3D strain fields, obtained by the ARAMIS 6M DIC system, confirms the good homogeneity of strain magnitudes over the useful zone of specimens. All details can be found in our previous report [18]

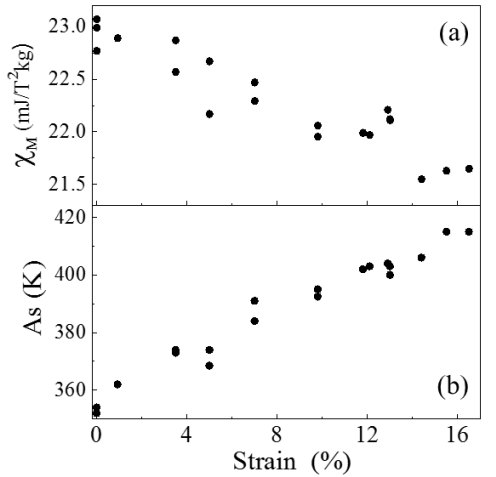

Figure 2. (a) Magnetic susceptibility $\chi_{M}$ of NiTi in martensite phase at $300 \mathrm{~K}$ and (b) Austenite start temperature As, as a function of strain amplitude.

In Fig.1, red and blue curves show $\chi$ as a function of temperature during the martensite-toaustenite transformation of the $5 \%$ (red) and $16.5 \%$ (blue) strained NiTi sample. They are compared to $\chi(\mathrm{T})$ cycle of the non-deformed NiTi sample (in black). Stretching modifies the magnetic response of NiTi in two ways. First, the martensite-to-austenite transition temperature (so-called Austenite start temperature As) is pushed toward higher temperature when strained, up to $415 \mathrm{~K}$ in case of $16.5 \%$ strain. The positive shift increases linearly with increasing strain (see Fig. 2(b)). This effect, known as stress-induced martensite stabilization and whose origin is still under debate [4$6,19]$, is one of the two phenomena which we focus on here. In Fig. 1, the second noticeable difference between the as grown and strained samples is the difference between magnetic susceptibility values at $300 \mathrm{~K}$ in $\mathrm{B} 19$ ' phase $\left(\chi_{\mathrm{M}}\right)$, whereas austenite susceptibility $\left(\chi_{\mathrm{A}}\right)$ is preserved at high temperature. Fig. 2(a) summarizes all our magnetic susceptibility measurements as a function of strain. $\chi_{M}$ is found to decrease monotonically when strain amplitude increases.
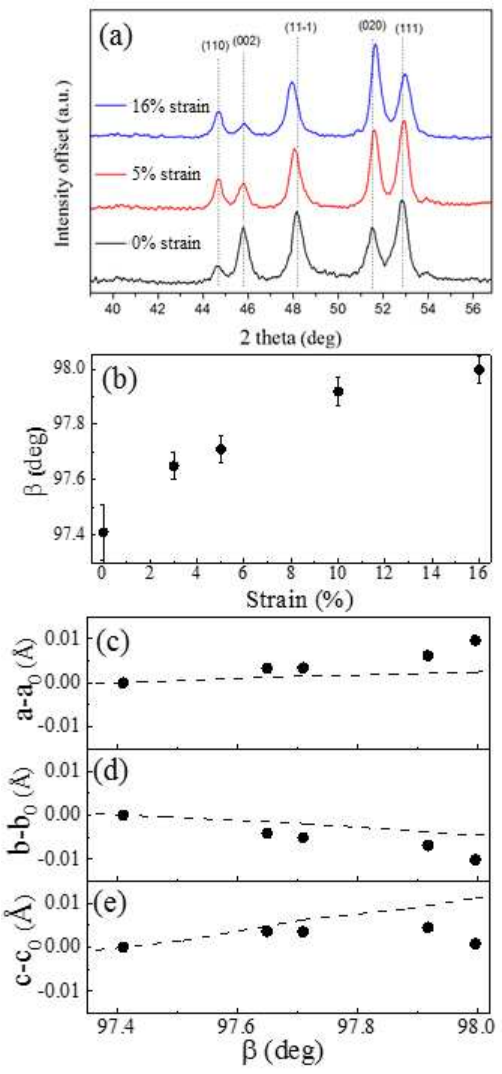

Figure 3. (a) Room temperature XRD measurements for $0 \%$ strained (black), $5 \%$ strained (red) and $16 \%$ strained (blue) martensite NiTi sheets. Dashed lines indicate the family of cristallographic planes corresponding to each intensity peak of the unstrained sample. (b) Monoclinic angle $\beta$ as a function of tensile strain amplitude deduced from XRD measurements. (c-e) Lattice parameters of martensite phase as a function of monoclinic angle $\beta$ extracted from XRD experiments and compared with theoretical values (dashed lines) from [20].

In order to access average lattice parameters as a function of temperature and strain, and to later use them in ab-initio calculations, we perform X-ray diffraction measurements (XRD) with a Co K $\alpha$ source. Heating is accomplished in-situ by means of a DHS 1100 oven at atmospheric pressure (Figure 3(a)). The measured lattice parameters of the unstrained B19' phase at $300 \mathrm{~K}$ are: $a=2.894 \AA, b=4.115 \AA, c=4.637 \AA$ and $\beta=97.41 \mathrm{deg}$, which are close to previous theoretical reports [20,21]. The B2 austenite phase parameter is $a_{A}=3.016 \pm 0.002 \AA$. To analyze the strain-induced change of martensite lattice, XRD is 
performed for five representative samples with various strain values ranging from 0 to $16 \%$ (Figure 3(a)). The monoclinic angle $\beta$ of the $\mathrm{B} 19^{\prime}$ phase increases with tensile strain and tends to saturate at high strain values. The saturation is due to the increasing amount of energy relaxation via plastic deformation (see Fig.3a). The same tendency as of $\beta$ is observed for both $a$ and $c$ parameters while it is inversed for $b$. In Figure 3 (b), a relative change of $a, b$ and $c$ parameters as a function $\beta$ matches quantitatively well earlier theoretical predictions obtained by ab-initio calculations for relaxed B19' lattices with fixed $\beta[20,21]$. Significant deviation only occurs for the $16 \%$ strained sample, most probably due to large level of plastic deformation. Interestingly, the austenite lattice parameter measured by XRD after heating, is found to be insensitive to the level of strain applied to the martensite state, and $a_{A}=3.016 \pm 0.002 \AA$. The main observed feature in the B2 XRD data is a broadening of the diffraction peak for larger strains, which we associate to microstresses induced by dislocation networks and/or twin domains reminiscent from B19' deformations [7,9].

Based on the XRD data, density Functional Theory (DFT) calculations of $\mathrm{Ni}_{50} \mathrm{Ti}_{50}$ are performed with the Vienna Ab-initio Simulation Package (VASP) [22]. The interactions between the valence electrons and the ionic core is described using the projectoraugmented wave (PAW) method and the calculations are performed with the generalized gradient approximation (GGA-PBE) [23,24]. Spin polarization is considered. A plane wave basis set for electron wave functions with cutoff energy of $500 \mathrm{eV}$ is used. Integrations in the Brillouin zone are performed using a k-grid generated according to the Monkhorst-Pack scheme: $33 \times 23 \times 23$ for the martensite NiTi. Density of states (DOS) calculations are performed with the tetrahedron method for Brillouin-zone integrations [25]. Atomic positions used for B 19 ' in all calculations are for $\mathrm{Ni}: x=0.0372, y=1 / 4, z=0.1752$ and for $\mathrm{Ti}: x=$ $0.4176, y=1 / 4, z=0.7164$. B2 and B19' total DOS as a function of energy are presented in inset in Fig.4(a). Our DFT calculations show no net atomic magnetic moment at rest for both crystal structures. The DOS at the Fermi level $D\left(E_{F}\right)$ is 0.72 states.atom ${ }^{-1} . \mathrm{eV}^{-1}$ for the martensite phase and 1.38 states.atom ${ }^{-1} \cdot \mathrm{eV}^{-1}$ for the austenite phase. It is interesting to note that both values agree well with two previous DFT calculations [26,27] but the martensite one is $25 \%$ lower than another value calculated by Bihlmayer et al. [28]. This discrepancy originates from the appearance of a DOS dip at $\mathrm{E}_{\mathrm{F}}$ (Fig. 4(a)) when considering a monoclinic angle around $97.8 \mathrm{deg}$ as in Ref. [26,27] while this dip is much reduced for an angle of $96.8 \mathrm{deg}$ as in Ref. [28]. We calculate that this dip at $E_{F}$ originates mostly from $\mathrm{Ni}$ and Ti d orbitals, which contribute equally to Pauli paramagnetism. Therefore, tuning of $\beta$ must allow to tune the density of states at $\mathrm{E}_{\mathrm{F}}$ and finally magnetic susceptibility.
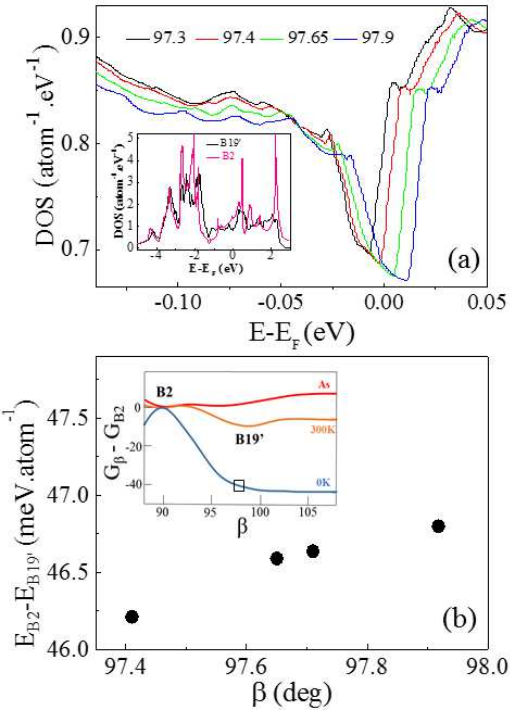

Figure 4. (a) Total DOS of martensite phase as a function of energy around Fermi level for various values of monoclinic angle $\beta$. Inset: Total DOS of martensite phase (black curve) with $\beta=97.4 \mathrm{deg}$ and austenite phase (pink curve) as a function of energy. (b) The energy difference between austenite and martensite state, as a function of calculated measured martensite $\beta$ angle. In inset, scheme of free energy as a function of $\beta$ for $0 \mathrm{~K}, 300 \mathrm{~K}$ and $A s$, as reported in Ref. [6]. The black open square corresponds to the region of interest in our study.

Using our DFT results in equation of Pauli susceptibility in the nearly-free electron model, $\chi_{\text {Pauli }}=$ $\mu_{\mathrm{B}}^{2} \cdot \mathrm{D}\left(\mathrm{E}_{\mathrm{F}}\right)$, and subtracting Landau diamagnetic term (1/3 of $\left.\chi_{\text {Pauli }}\right)$, we obtain theoretical values: $\chi_{\mathrm{M}}{ }^{\mathrm{T}}=2.9$ $\mathrm{mJ} . \mathrm{T}^{-2} \cdot \mathrm{kg}^{-1}$ in martensite phase and $\chi_{\mathrm{A}}{ }^{\mathrm{T}}=5.5 \mathrm{~mJ} \cdot \mathrm{T}^{-2} \cdot \mathrm{kg}^{-}$ ${ }^{1}$ in austenite phase. Experimental values are 7.6 and 5.8 times larger respectively. Similar discrepancy is reported for many Pauli paramagnetic metals such as $\mathrm{Pd}$ (factor of 10) [29] or $\mathrm{Ni}_{50} \mathrm{Zr}_{50}$ (factor of 6) [30]. Electronic exchange interaction in nearly-free electron model [29-31] account for such an enhancement of magnetic susceptibility. In NiTi, we find an interaction energy of $1.1 \mathrm{eV}$ in $\mathrm{B} 19$ ' and $0.55 \mathrm{eV}$ in $\mathrm{B} 2$, in line with an earlier analytical prediction by Mitchell et al. [11]. In Fig. 4(a), DOS as a function of energy is 
zoomed-in around $E_{F}$ and plotted for the different B19' unstrained and strained B19' lattices found by XRD in Fig.3. We extended our set of theoretical data with one more point at lower $\beta$ angle $\left(\beta=97.3^{\circ}\right)$ considering the lattice parameters calculated in Ref. [20]. As $\beta$ increases, $D\left(E_{F}\right)$ is found to decrease because DOS dip at $E_{F}$ shifts toward larger energy, gets deeper and wider. An overall decrease of $D\left(E_{F}\right)$ by 0.04 atom $^{-1} \mathrm{eV}$ ${ }^{1}$ as observed in Fig. 4(a) would translate to a reduction of $\chi_{\mathrm{M}}$ by $1.2 \mathrm{~mJ} . \mathrm{T}^{-2} \cdot \mathrm{kg}^{-1}$, in good agreement with the experimental data in Fig. 2(a). Therefore, we conclude that NiTi is an exchange-enhanced Pauli paramagnet whose magnetic susceptibility is sensitive to strain because of its dependence to B19' lattice shear.

The correlation between $A s$ and $\beta$ is revealed when comparing Fig. 2(b) and Fig. 3(a). Between 0 and $10 \%$ strain, $\beta$ linearly increases by 0.5 degrees while As rises linearly by $40 \mathrm{~K}$. Although here only the shear is affected and no chemical modification are operated, the correlation ratio $80 \mathrm{~K} / \mathrm{deg}$ is quite similar to those obtained when tuning Hf concentration in NiTiHf [2] or when tuning Ni concentration in NiTi [1]. In order to enlighten the origin of the influence of B19' shear on $A s$ increase with tensile strain, the difference of energy (enthalpy) between B19' and B2 state, $E_{B 2}$ $E_{B 19}$, calculated for $0 \mathrm{~K}$, is plotted in Fig. $4(\mathrm{~b})$ as a function $\beta$ angle. It rises when $\beta$ is enhanced. In other words, the calculated B2 energy being constant with strain (since the measured lattice parameter by XRD is constant), only B19' energy is found to decrease by 0.6 $\mathrm{meV}$.atom ${ }^{-1}$ when $\beta$ increases by 0.5 degrees. Such decrease of energy for NiTi B19' state with increasing $\beta$ agrees with the many ab-initio calculations at $0 \mathrm{~K}$ reported in the literature $[6,20]$. The link between the variation of enthalpy at $0 \mathrm{~K}$ and the martensite-toaustenite transition temperature above room temperature can be understood by considering the difference of free energy $\mathrm{G}_{\mathrm{B} 2}-\mathrm{G}_{\mathrm{B} 19}$, $=\left(\mathrm{H}_{\mathrm{B} 2}-\mathrm{H}_{\mathrm{B} 19}\right.$ ) $\mathrm{T}^{*}\left(\mathrm{~S}_{\mathrm{B} 2}-\mathrm{S}_{\mathrm{B} 19}\right)$ where $\mathrm{G}$ is the free energy, $\mathrm{H}$ is the enthalpy at $0 \mathrm{~K}, \mathrm{~T}$ the temperature and $\mathrm{S}$ the entropy. Due to the significant difference of phonon-based entropy of B2 and B19', $\mathrm{G}_{\mathrm{B} 2}-\mathrm{G}_{\mathrm{B} 19}$, almost linearly decreases with increasing temperature and reaches zero for a value just below $A s[1,6]$, as schemed in inset of Fig.4(b). Therefore, any variation of enthalpy at $0 \mathrm{~K}$ leads to a shift of As. We conclude that martensite stabilization can be produced in $\mathrm{NiTi}$, without changing its composition, by engineering straininduced shear of B19' lattice.

In summary, we present $\mathrm{X}$-ray diffraction and magnetometry studies of a $\mathrm{Ni}_{49,4} \mathrm{Ti}_{50,6}$ alloy free standing film as a function of tensile strain amplitude. We characterize a strain-dependent shear-like trend in
B19' lattice with the monoclinic angle $\beta$ increasing from 97.4 to $98 \mathrm{deg}$, which we correlate to a reduction of magnetic susceptibility $\left(\chi_{\mathrm{M}}\right)$ and a raise of martensite-to-austenite transition temperature (As). Using DFT calculations, we show that dependence in of NiTi exchange-enhanced Pauli paramagnetism originates from the shift and the deepening of a density of state dip at the Fermi level, while strain-induced martensite stabilization is coherent with the lowering of B19' state enthalpy with shear.

\section{Acknowledgements}

The authors thank L. Calmels, P. Scheid and J. Gorchon for fruitful discussions, as well as S. Migot and J. Ghanbaja for TEM analysis. This work was supported partly by CRYOSCAN SAS, by the french PIA project "Lorraine Université d'Excellence", reference ANR-15-IDEX-04-LUE, and by SONOMA project co-funded by FEDER-FSE Lorraine et Massif des Vosges 2014-2020, a European Union Program.

\section{References}

[1] J. Frenzel, A. Wieczorek, I. Opahle, B. Maaß, R. Drautz, G. Eggeler, Acta Materalia 90, 213 (2015)

[2] H. Sehitoglu, Y. Wu, L. Patriarca, G. Li, A. Ojha, S. Zhang, Y. Chumlyakov, M. Nishida, Shape Mem. Superelasticity 3, 168 (2017)

[3] X. Yang, L. Ma, J. Shang, Scientific Rep. 9, 3221 (2019) [4] J. Cui, Y.S. Chu, O.O. Famodu, Y. Furuya, J. HattrickSimpers, R.D. James, A. Ludwig, S. Thienhaus, M. Wuttig, Z. Zhang, I. Takeuchi, Nature Mater, 5, 286 (2006)

[5] M. Zarinejad, Y. Liu, Adv. Funct. Mater. 18, 2789 (2008) [6] J.B. Haskins, A.E. Thompson, J.W. Lawson, Phys. Rev. B 94, 214110 (2016)

[7] Y. Liu and D. Favier, Acta Materialia 48, 3489 (2000)

[8] G. Tan and Y. Liu, Intermetallics, 12, 373 ( 2004)

[9] P. Chowdury, H. Sehitoglu, Progress in Materials sciences 88,49 (2017)

[10] F.E. Wang, B.F. DeSavage, W.J. Buehler, and W.R Hosler, J. Appl. Phys. 39, 2166 (1968)

[11] M.A. Mitchell, F.E. Wang, and J.R. Cullen, J. Appl. Phys. 45, 3337 (1974)

[12] A.V. Brodovoi, N.V. Goncharuk, G.V. Lashkarev, I.F Martynova, A.L. Mirets, V.V. Skorokhod, S.M. Solonin, Powder Metall Met Ceram, 32, 355 (1993)

[13] M.-S. Choi, T. Fukuda, and T. Kakeshita, Scripta Materialia 53, 869 (2005)

[14] D. Chovan, A. Gandhi, J. Butler, S.A.M. Tofail, J. Magn. Magn. Mater. 452, 451 (2018)

[15] T. Hana, Y. Sohna, S. Jin Parka, Y.-C. Kimb, K. Sik Leec, H. Sung Kimd, S.-G. Yoona, D. Kima, J. Hyun Hana, Materials Science \& Engineering C 98, 1 (2019)

[16] R. Lima de Miranda, C. Zamponi, and E. Quandt, Adv. Engineer. Mater., 15, 66 (2013) 
[17] J. Frenzel, E. P. George, A. Dlouhy, Ch. Somsen, M. F.X. Wagner, and G. Eggeler, Acta Mater., vol. 58, no. 9, pp. 3444-3458, May 2010

[18] A. Kyianytsia, M. Ponçot, A. Letoffe, P. Boulet , S Migot, J. Ghanbaja, I. Cinar, R. Lima de Miranda, C. Bechtold, B. Kierren, O. Ozatay, and T. Hauet, Appl. Phys. Lett. 115, 222402 (2019)

[19] S. Belyaev, N. Resnina, E. Iaparova, A. Ivanova, T. Rakhimov, V. Andreev, J. Alloys and Compounds 787, 1365 (2019)

[20] X. Huang, G.J. Ackland, and K. M. Rabe, Nature Mater 2, 307 (2003)

[21] M.F.-X. Wagner, W. Windl, Acta Materialia, 56, 6232 (2008)

[22] G. Kresse and J. Furthmüller, Computational Materials Science, 6, 15 (1996)

[23] G. Kresse and D. Joubert, Phys. Rev. B, 59, 1758 (1999) [24] J.P. Perdew, K. Burke, and M. Ernzerhof, Phys. Rev. Lett., 77, 3865 (1996)

[25] P. E. Blöchl, O. Jepsen, and O. K. Andersen, Phys. Rev. B, 49, 16223 (1994)

[26] Y. Kudoh, M. Tokonami, S. Miyazaki, K. Otsuka, Acta Metall. Mater. 33, 2049 (1985)

[27] Y. Y. Ye, C. T. Chan, and K. M. Ho, Phys. Rev. B, 56, 3678 (1997)

[28] G. Bihlmayer, R. Eibler, A. Neckel, J. Phys. : Condens. Matter 5, 5083 (1993)

[29] F. M. Mueller, A. J. Freeman, J. O. Dimmock, and A. M. Furdyna, Phys. Rev. B 1, 4617 (1970)

[30] Z. Altounian, J.O. Strom-Olsen, Phys. Rev. B 27, 4149 (1983)

[31] J. M. D. Coey, "Magnetism and Magnetic Materials by J. M. D. Coey," Cambridge Core (2010)

Data Availability Statement

The data that support the findings of this study are available from the corresponding author upon reasonable request. 


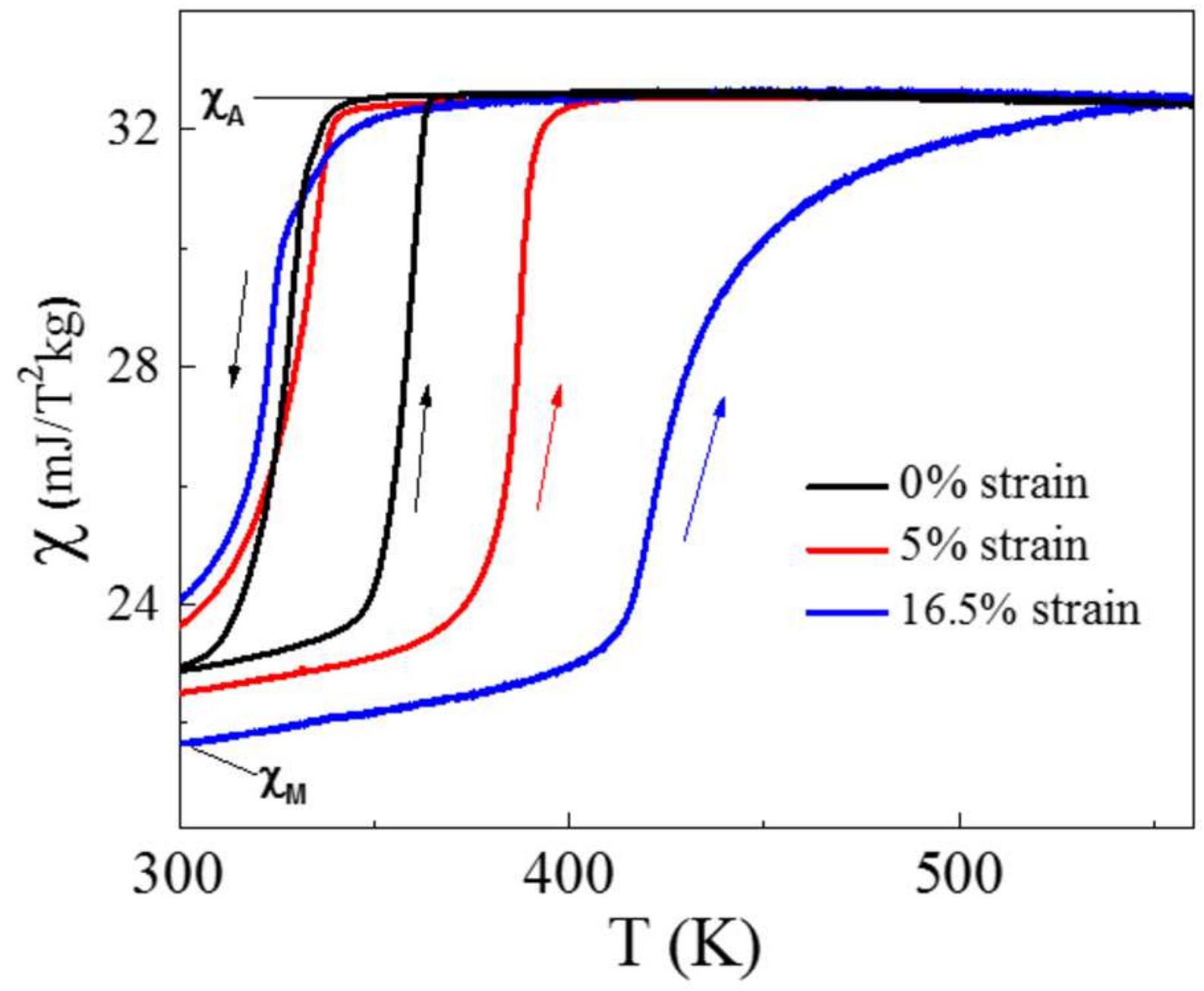

兄耪言 


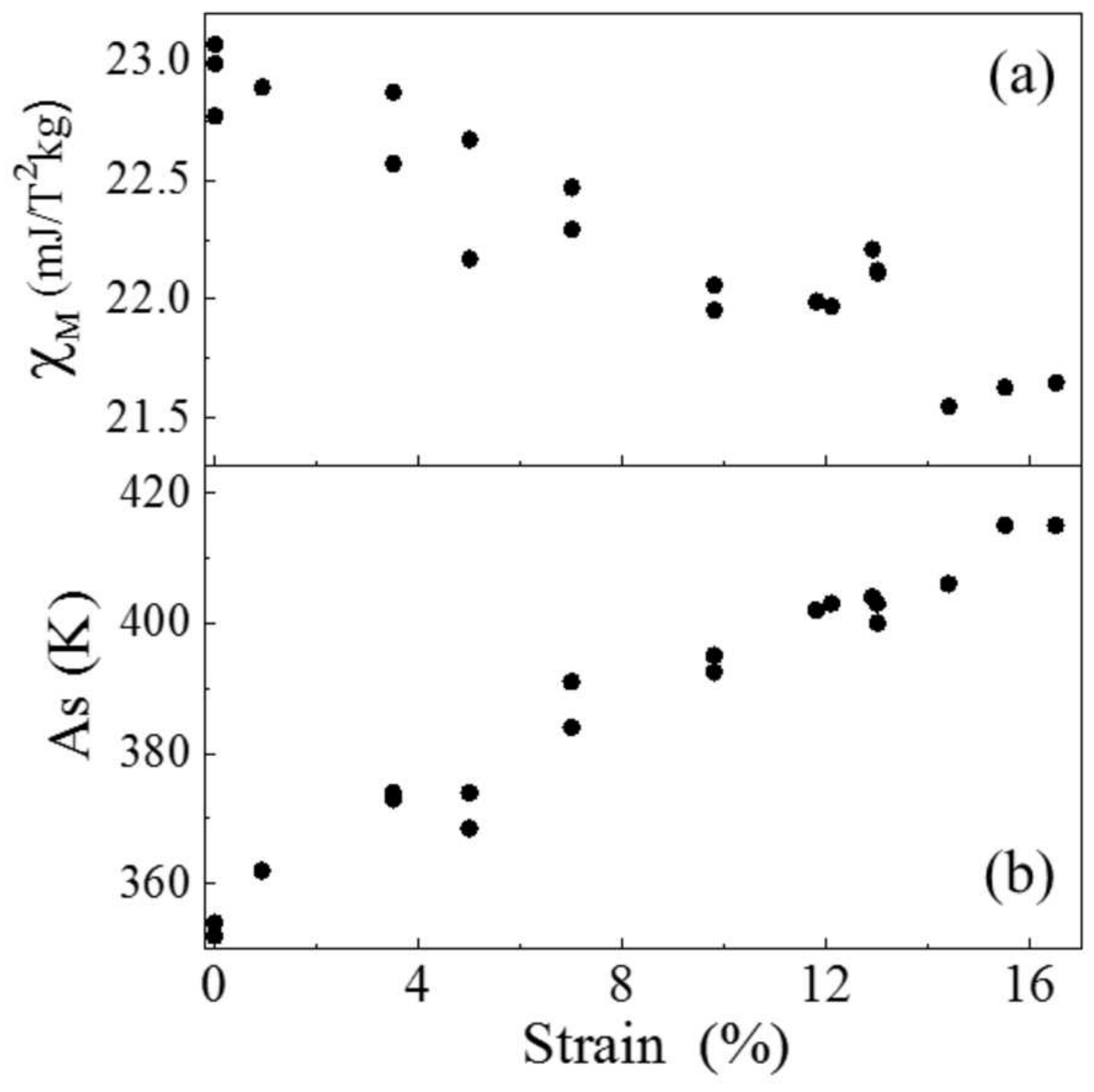

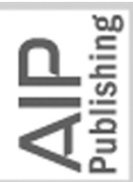



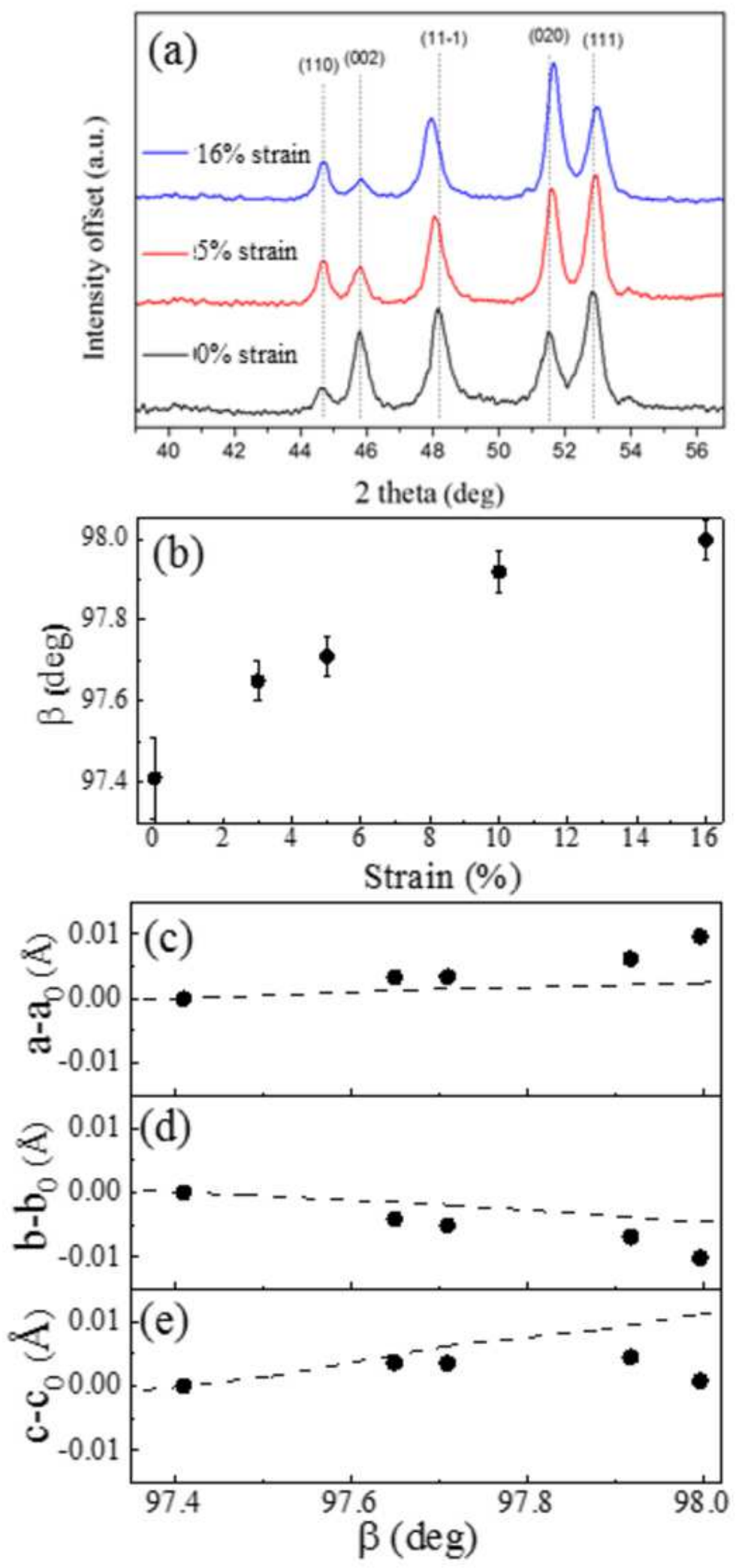

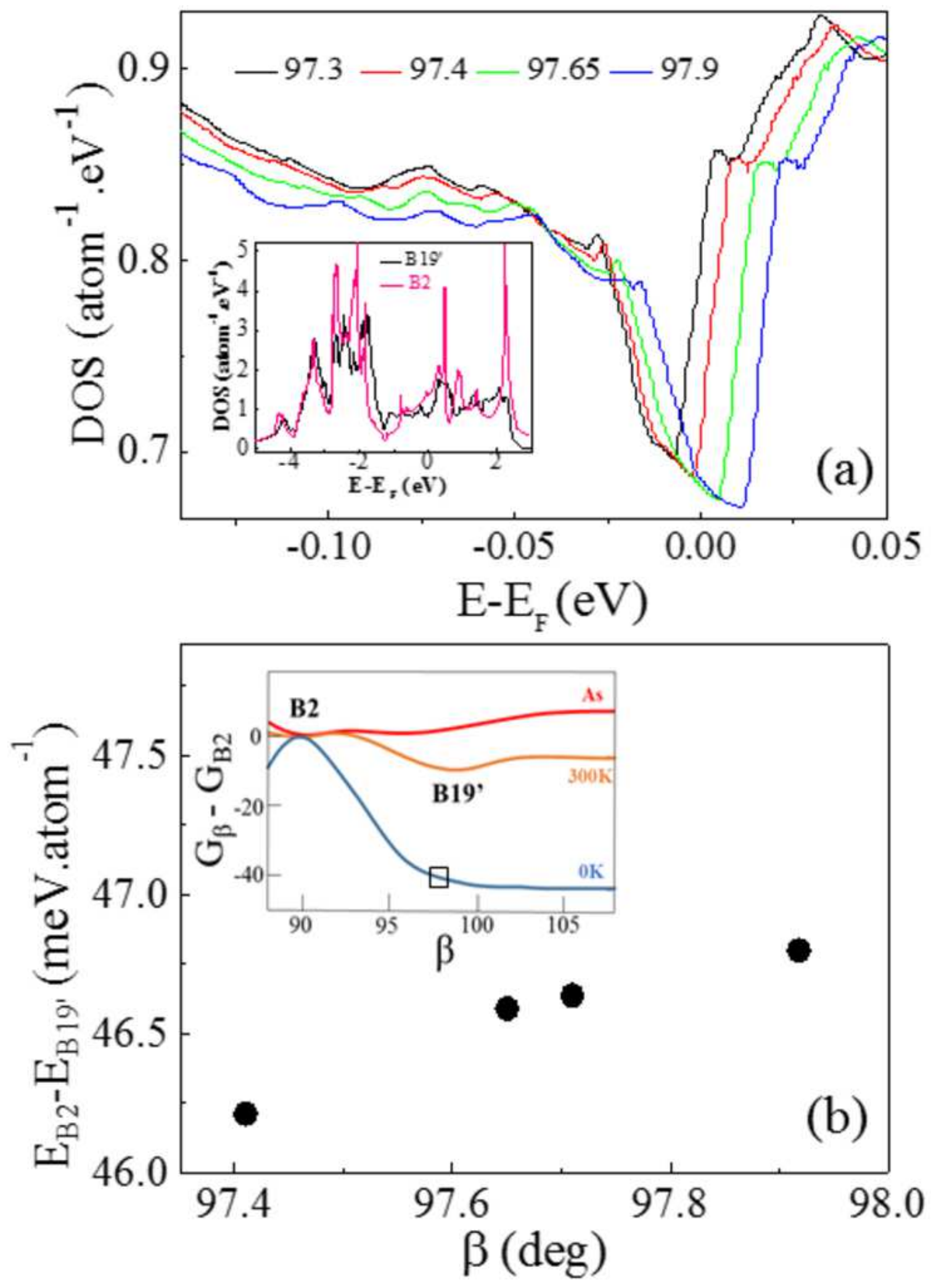